\title{
0 custeio-meta para o desenvolvimento de habitações de interesse social: diretrizes a partir da comparação de duas modalidades de provisão
}

\author{
Target costing for the development of social housing \\ projects: guidelines based on a comparison between two \\ forms of provision
}

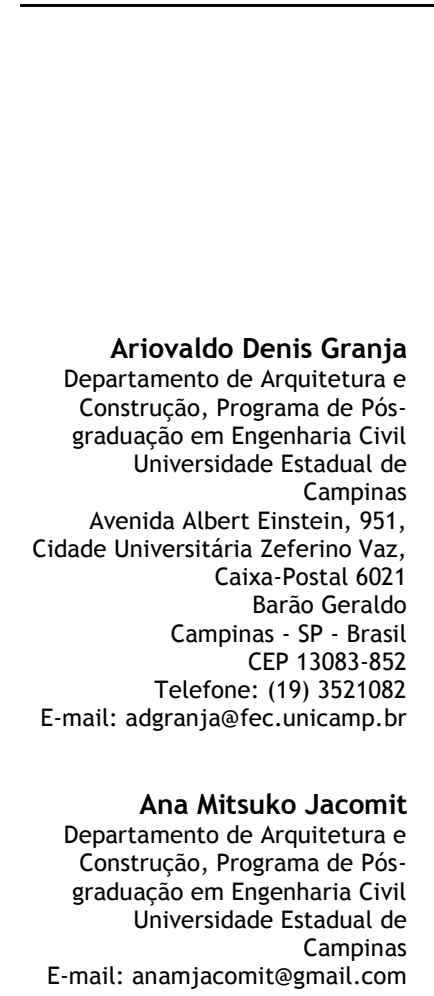

Sidnei Junior Guadanhim Departamento de Arquitetura e Urbanismo, Centro de Tecnologia e Urbanismo Universidade Estadual de Londrina Caixa-Postal 6001 Rod. Celso Garcia Cid, PR 445, km Londrina - PR - Brasil CEP 86055-900 Tel.: (43) 3371-4535 E-mail: sjg@uel.br

Ercília Hitomi Hirota Departamento de Construção Civil, Centro de Tecnologia e Urbanismo Universidade Estadual de Londrina Tel.: (43) 3371-4460 E-mail: ercilia@uel.br

Recebido em 25/10/2010 Aceito em 15/03/2011

\section{Ariovaldo Denis Granja \\ Ana Mitsuko Jacomit \\ SidneiJunior Guadanhim \\ Ercília Hitomi Hirota}

\section{Resumo}

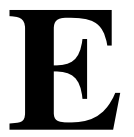

ste artigo apresenta resultados de uma pesquisa que teve como objetivo investigar a aplicação do custeio-meta como uma abordagem alternativa ao processo de desenvolvimento de empreendimentos habitacionais de interesse social (EHIS) atualmente utilizado por companhias públicas de provisão habitacional no Brasil. A estratégia de pesquisa consistiu no estudo dos fatores que influenciam uma implementação do custeiometa, a partir de dois estudos de casos, e na identificação das características de EHIS que poderão influenciar, positiva ou negativamente, uma implementação desta abordagem por companhias públicas de provisão habitacional. A análise dos fatores de Cooper e Slagmulder forneceu a base teórica para a identificação de oportunidades para a adoção do custeio-meta no contexto analisado, e a comparação de duas modalidades diferentes de provisão habitacional foi utilizada para a formulação das inferências apresentadas. A análise das características dos EHIS permitiu a identificação de barreiras e oportunidades para a adoção do custeio-meta no desenvolvimento deste tipo de empreendimento. $\mathrm{O}$ artigo aponta, ao final, diretrizes para a implementação desta abordagem para o desenvolvimento de EHIS.

Palavras-chave: Custeio-meta. Processo de desenvolvimento de produto na construção. Habitação de interesse social. Gerenciamento de custos.

\section{Abstract}

This paper presents the results of a research study aimed at investigating the application of target costing as an alternative approach for the development process of Social Housing Projects (SHPs) currently employed by public housing providers in Brazil. The research strategy consisted of the study of the factors that influence the implementation of target costing, based on two case studies and on the identification of the SHP characteristics that could influence, positively or negatively, the implementation of this approach by public housing companies. The analysis of Cooper and Slagmulder's factors provided the theoretical framework for identifying opportunities for the adoption of target costing in SHPS. The comparison between two different forms of housing provision was the basis for formulating the inferences presented. The analysis of the SHPs' characteristics allowed the identification of hindrances and opportunities for the implementation of target costing in this type of endeavor. This paper presents guidelines for the use of this approach in the development of social housing projects.

Keywords: Target costing. Product development process in construction. Social housing projects. Cost management. 


\section{Introdução}

A necessidade de atendimento à demanda por habitações para a população de baixa renda, com recursos limitados, representa um importante desafio. Estudos recentes mostram que tal desafio envolve tanto a compreensão das necessidades dos clientes nessa faixa de renda, com sua dinâmica e complexidade, como os aspectos técnicos da gestão dos requisitos dos diversos agentes envolvidos no processo de desenvolvimento desses produtos, quais sejam: usuários, agente financeiro, construtoras, administradoras dos empreendimentos, projetistas, agências protetoras do meio ambiente, poder público, entre outros (MIRON, 2008). Nesse sentido, a busca do equilíbrio entre recursos disponíveis e a agregação de mais valor aos empreendimentos habitacionais de interesse social (EHIS) caracterizam-se como tarefas da maior relevância, diante do déficit habitacional de 5,5 milhões de domicílios (BRASIL, 2010), com dados de 2008.

Ao analisar as abordagens adotadas pela indústria de manufatura para desenvolvimento de produtos mais competitivos no mercado, sem deixar de atender aos objetivos de lucratividade das empresas, identificou-se o custeio-meta (CM) como uma abordagem propícia à integração dos conceitos de valor, desempenho e custos no desenvolvimento de produtos. Assim, a pesquisa que originou o presente artigo almejou investigar o potencial de aplicação do CM como uma abordagem alternativa ao processo de desenvolvimento de EHIS atualmente utilizado por companhias públicas de provisão habitacional no Brasil.

Estudos anteriores sobre CM em EHIS no Brasil limitaram-se a estudar isoladamente programas existentes para provisão habitacional (GUADANHIM; HIROTA; LEAL, 2010; JACOMIT; GRANJA, 2010). Nesta pesquisa, foram desenvolvidos dois estudos paralelos analisando, em detalhes, o processo de desenvolvimento de EHIS em duas instituições públicas de promoção de habitação de interesse social. Esses estudos resultaram na identificação de barreiras e oportunidades para a implementação do CM nesse contexto, com respaldo teórico na análise de fatores identificados por Cooper e Slagmulder (1997), que afetam os resultados da aplicação dessa abordagem no contexto da manufatura. A análise comparativa desses dois estudos resultou em diretrizes para a implementação do CM no desenvolvimento de EHIS, consistindo, dessa forma, na identificação de contextos mais favoráveis para a sua adoção no desenvolvimento de empreendimentos de habitação de interesse social.

\section{Origens do custeio-meta}

O CM teve origem nas estratégias de gerenciamento do lucro desenvolvidas ao longo dos últimos 30 anos por empresas japonesas, a partir dos princípios da técnica de Engenharia de Valor (EV). Trata-se de um sistema de planejamento de lucros e custos focado em preço, consumidor, projeto e funcionalidade (ANSARI; BELL, 1997), e cuja principal característica é a sua aplicação desde as primeiras fases de concepção de um produto.

Há diversas contribuições para a definição do conceito, nas quais se observa a existência de diferentes enfoques. Por exemplo, Cokins (2002) define CM como uma técnica de modelagem de custos aplicada no início do ciclo de vida do produto, durante a fase de conceituação e projeto, que, a partir da identificação do preço que os consumidores estão dispostos a pagar por um produto, determina as margens de lucro e os custos permissíveis. Na mesma linha, Monden (1995) define CM como um sistema para administração do lucro que se insere na etapa de desenvolvimento do produto, com dois objetivos:

(a) reduzir os custos de novos produtos; garantindo o lucro requerido e satisfazendo os níveis de qualidade exigidos pelo mercado; e

(b) motivar toda a cadeia a alcançar o lucro-meta durante o desenvolvimento de novos produtos.

Por outro lado, Nicolini et al. (2000) definem CM como uma estratégia para o desenvolvimento de novos produtos que envolve todos os agentes do processo, objetivando a redução dos custos do ciclo de vida (Life-Cycle Costs). Para esses autores, essa redução de custos deve assegurar qualidade, confiabilidade e os demais requisitos do cliente a partir do exame cuidadoso de todas as ideias possíveis durante os estágios de planejamento, pesquisa e prototipagem. Para tanto, o domínio pleno dos custos deve ocorrer desde as primeiras fases de concepção e acompanhar o processo de desenvolvimento do produto (PDP) até a fase de uso e operação.

Da mesma forma, Cooper e Slagmulder (1997) argumentam que o CM é mais do que uma técnica ou ferramenta de gestão de custos e lucros, é uma estratégia de desenvolvimento de produtos, na qual o custo de produção deixa de ser uma consequência do projeto para se converter em parâmetro do projeto (IBUSUKI; KAMINSKY,

54 Granja, A. D.; Jacomit, A. M.; Guadanhim, S. J.; Hirota, E. H. 
2007; BALLARD; REISER, 2004). Essa estratégia é eficaz, segundo Cooper e Slagmulder (1997), na busca do equilíbrio entre custo e preço, qualidade e funcionalidade, elementos que constituem o conceito de tripé de sobrevivência da empresa no mercado. Segundo esse conceito, não é possível reduzir excessivamente o custo sem prejudicar a qualidade e a funcionalidade. Por outro lado, não se pode agregar funções e ampliar de forma significativa a qualidade sem que isso impacte no custo e, consequentemente, no preço.

$\mathrm{O}$ cerne do $\mathrm{CM}$ reside na ideia simples de que o custo-meta deve ser obtido pela subtração da margem de lucro do preço de mercado. Contudo, essa simplicidade esconde um rico e complexo processo, o qual, embora possa variar consideravelmente, possui estrutura básica composta de três etapas: custeio baseado no mercado; custeio em nível do produto; e custeio em nível de componentes. $\mathrm{O}$ custeio baseado no mercado é usado para estabelecer o custo permissível para o produto, que o torne competitivo. O custeio em nível de produto estabelece o custo-meta do produto, com o emprego da EV, considerando as características de desempenho e requisitos do cliente. Por último, o custeio em nível do componente é usado para estabelecer o custo-meta dos componentes do produto, o que envolve, necessariamente, a cadeia de suprimentos. Este implica ações cooperativas e envolvimento dos fornecedores, de forma que os componentes mantenham a qualidade dentro do custo-meta estabelecido para o componente (COOPER; SLAGMULDER, 1997).

Com base na literatura sobre o tema, em síntese, um cenário hipoteticamente indicado para a aplicação do CM contemplaria os seguintes princípios:

(a) a referência básica para todo o processo é o mercado, seu ambiente competitivo e os requisitos do cliente; em se tratando de mercados com baixa concorrência, como nos casos em estudo no presente artigo, o foco não necessariamente será o mercado, mas a redução dos custos ao longo do ciclo de vida, o aumento de valor entregue, o atendimento a recursos específicos de financiamento que o cliente tem a disposição, entre outros;

(b) é necessária uma gestão eficiente de informações e custos, bem como o domínio dos custos, e não dos preços dos componentes e serviços, e do through life cost, ou custo ao longo do ciclo de vida do produto;

(c) a avaliação deve ser contínua, pois o processo de aplicação do CM caracteriza-se como cíclico e não linear; (d) a utilização combinada de técnicas como análise de valor e engenharia de valor, associadas à criatividade da equipe de projeto e estruturação dos custos baseada em funções a serem desempenhadas pelo produto, permite a avaliação do valor agregado e percebido pelo usuário; e

(e) toda a cadeia no PDP - investidores, projetistas, fornecedores, construtores, vendedores e clientes - deve ser envolvida, com a formação de equipes multidisciplinares e a implementação de peças e componentes modulares ou padronizados.

\section{CM na construção civil}

Jacomit e Granja (2008) apontam pesquisas recentes com indicações favoráveis à ideia de implantação do $\mathrm{CM}$ na construção civil e ressaltam, inclusive, que empresas construtoras japonesas têm obtido resultados positivos com a sua aplicação (YOOK; KIM; YOSHIKAWA, 2005). Nicolini et al. (2000) discutem a experiência de utilização do CM no desenvolvimento de instalações militares no Reino Unido, cujo custo-meta foi obtido de dados históricos e incluiu o processo de projeto. Segundo a análise desses autores, as particularidades da indústria da construção naquele país inviabiliza o uso do CM. Entre as características mencionadas encontram-se o uso de técnicas construtivas rudimentares, as quais não contemplam, por exemplo, componentes padronizados, e a falta de integração entre diferentes especialidades de projetos, salientando a ocorrência, bastante comum, de problemas de integração entre projeto e obra.

Ballard e Reiser (2004) apresentam a aplicação do $\mathrm{CM}$ no desenvolvimento de um ginásio de esportes em uma universidade norte-americana, no qual o custo-meta foi estabelecido não com base no mercado, mas em função da verba disponível devido a uma doação de ex-aluno. $\mathrm{O}$ processo de projeto foi parte integrante da estratégia, mas a equipe foi formada após os esquemas iniciais terem sido definidos, ou seja, as fases iniciais (préprojeto) não ocorreram sob a abordagem do $\mathrm{CM}$. Mesmo assim, a conclusão dos autores é positiva com relação à aplicabilidade dessa abordagem, no contexto analisado.

Um estudo realizado no Brasil é reportado por Robert e Granja (2006). Trata-se de uma rede de unidades de varejo, cujo custo-meta havia sido estabelecido com base em dados históricos de obras da rede. Embora não tenha incluído o processo de projeto - o que aproxima o conceito adotado por esses autores daquele defendido por Monden (1995) -, os resultados obtidos em redução de custo, mantendo-se a qualidade com 
foco nos requisitos dos clientes, também indicaram a aplicabilidade do CM na construção civil.

Ballard (2006) aborda um aspecto particular para a aplicação do $\mathrm{CM}$ na construção civil: o de que é necessário repensar as fases iniciais de concepção do produto. $\mathrm{O}$ autor busca o estabelecimento de fases cujas entregas de projeto devam sofrer constantes retroalimentações e contemplar informações suficientes a cada passo no desenvolvimento do produto. A fase inicial de projeto, também chamada de definição de projeto, ou ainda pré-projeto, consiste em uma etapa cíclica, que envolve três elementos primários: o primeiro refere-se ao levantamento dos objetivos do cliente ou empreendedor; o segundo, aos meios para se atingirem esses objetivos, através da ferramenta de projeto (design); e, por fim, ao entendimento das limitações ou condicionantes do processo. Tais elementos podem ser alterados durante o processo de projeto, desde que de forma alinhada e mutuamente consistente. É nessa fase que os problemas de projeto são gerados para serem resolvidos posteriormente, em fase de detalhamentos e aperfeiçoamentos dos desenhos. Assim, a compreensão clara do problema é fundamental. Isso não exclui a avaliação de soluções alternativas na fase pré-projeto. Muitas vezes a exploração de soluções é necessária para o entendimento do problema.

Embora seja comum na construção civil que cada edifício seja concebido e projetado para um cliente único e específico, introduzir a abordagem $\mathrm{CM}$ na construção é um objeto de pesquisa desafiador e, ao mesmo tempo, recompensador (BALLARD, 2006). Nos casos expostos acima não houve uma aplicação plena de todas as premissas teóricas e recomendações oriundas da indústria manufatureira:

(a) em especial, a premissa do preço estabelecido pelo mercado não foi testada;

(b) o envolvimento da cadeia ocorre parcialmente;

(c) os fornecedores de materiais de construção em geral são maiores do que as empresas construtoras, limitando a margem de negociação e o pleno envolvimento dos fornecedores no processo desde o início; e

(d) ainda é difícil trabalhar com o custo ao longo do ciclo de vida do produto no subsetor edificações, tendo em vista a falta de dados de confiança.

Apesar de inconsistências metodológicas, em todos os casos citados foi possível verificar algum ganho, seja na redução dos custos, na eficiência na produção ou na melhoria da qualidade. Assim, justificam-se os estudos sobre aplicação dessa abordagem na construção civil. $O$ contexto específico da produção de EHIS é analisado nesta pesquisa, já que tais empreendimentos apresentam algumas características que podem favorecer uma implementação do CM, quais sejam:

(a) a pressão externa da concorrência, prevista na teoria como um fator favorável, pode equivaler às condições impostas pelos órgãos financiadores;

(b) o custo-meta extraído do mercado já existe, consistindo nos limites de financiamento dos programas e na capacidade de endividamento dos clientes e suas exigências por meio dos dados das companhias de habitação;

(c) a produção em série de habitações aproxima esse tipo de produto daqueles desenvolvidos na manufatura, origem do CM; e

(d) o padrão de exigência dos usuários é crescente, o que obriga as empresas a entregarem mais valor sem aumentar o preço final.

\section{Método de pesquisa}

A estratégia adotada foi o desenvolvimento de estudo de caso comparativo, diante da possibilidade de analisar o PDP de duas companhias públicas promotoras de EHIS distintas, tanto em termos de estrutura como de procedimentos adotados no PDP.

\section{Companhia de Habitação A}

A pesquisa realizada na Companhia de Habitação A envolveu:

(a) uma revisão da literatura sobre CM, com a análise dos fatores que influenciam uma aplicação do CM; e

(b) caracterização do contexto de EHIS, mediante a realização de um estudo de caso exploratório.

$\mathrm{O}$ estudo de caso exploratório foi conduzido em uma companhia habitacional pública que atua no Estado de São Paulo e que executa programas habitacionais voltados para a população de baixa renda. A coleta de dados foi realizada ao longo de 1 ano, por meio de:

(a) entrevistas semiestruturadas com responsável da área de orçamentos da companhia e da área de projetos, pessoalmente e por email;

(b) análise de documentos (plantas, memoriais, planilha orçamentária, contratos, termos de referência); e

(c) pesquisa no site da companhia. 


\section{Companhia de Habitação B}

O estudo na Companhia de Habitação B foi desenvolvido a partir de revisão de literatura com foco na aplicabilidade do CM no processo de desenvolvimento de produtos na manufatura e sua transferência para a construção civil, e na análise dos resultados de dois estudos realizados anteriormente na mesma companhia. O primeiro deles, desenvolvido por Gomes, Guadanhim e Hirota (2006), resultou no mapeamento do PDP do Programa de Arrendamento Residencial (PAR), a partir das diretrizes propostas por Miron e Formoso (2003) para gestão de requisitos de cliente, consistindo nas etapas de identificação dos principais clientes, identificação dos requisitos dos clientes, identificação dos tomadores de decisão e formalização das relações cliente-fornecedor (mapa). Os dados foram coletados por meio de entrevistas semiestruturadas e análise de documentos.

O outro estudo, desenvolvido por Simões, Takinami e Hirota (2008), resultou em um mapa da cadeia de negócios de empreendimentos do PAR, nos quais essa companhia atuava como um dos agentes da cadeia. Esse estudo partiu de uma análise documental, envolvendo a legislação e a regulamentação do programa, para compreender o processo de desenvolvimento de empreendimentos e identificar oportunidades e riscos presentes nesse negócio. Posteriormente, foram coletadas informações adicionais para detalhamento do processo na Companhia $\mathrm{B}$, por meio de uma série de três entrevistas com o diretor técnico, responsável pelo Programa. A ferramenta adotada para a realização dessas entrevistas foi o mapa de fluxo de processo, no qual os dados coletados foram organizados. A cada entrevista o mapa era reformulado, acrescentando-se as informações colhidas, até a versão final, considerada fidedigna pelo diretor técnico.

Para a análise dos dois casos, foram adotados como parâmetros os fatores que influenciam positiva ou negativamente a aplicação do $\mathrm{CM}$, dependendo das características de cada empresa ou setor, identificados por Cooper e Slagmulder
(1997). Esses autores ressaltam, porém, que tais fatores são essencialmente contextuais, não havendo um cenário ideal aplicável genericamente a todos os casos. O Quadro 1 apresenta as características ideais de uma empresa, segundo Cooper e Slagmulder (1997), para que ela possa usufruir do maior número de benefícios com uma aplicação do CM. Os fatores de Cooper e Slagmulder (1997) mencionados no Quadro 1, os quais nortearam a análise dos EHIS discutidos neste artigo, foram desenvolvidos a partir da análise de dados coletados em empresas japonesas, oriundas principalmente da indústria automobilística, de eletrônicos e de maquinário pesado.

\section{Resultados e discussão}

Em seguida, apresentam-se os resultados e as discussões comparativas entre as Companhias de Habitação A e B.

\section{0 processo de desenvolvimento de EHIS na Companhia de Habitação A}

O fluxograma da Figura 1 apresenta os principais passos no desenvolvimento de um EHIS sob o regime de contratação por empreitada global de acordo com levantamento realizado na Companhia de Habitação A. Esta companhia já atuou no desenvolvimento ou no financiamento de 439.161 unidades habitacionais sob os mais diversos regimes de contratação e de execução, como, por exemplo, autoconstrução, mutirão, administração direta, cartas de crédito, empreitada global e integral. A implementação de um programa de habitação de interesse social se inicia com a identificação da demanda por esse tipo de habitação em determinada região do estado e pela determinação da solução de atendimento da demanda. A demanda é caracterizada por famílias residentes no município em questão, não proprietárias de imóveis e com renda entre 1 e 10 salários mínimos. Para a escolha da solução de atendimento há um grande número de opções, como as descritas acima, entre elas a opção por empreitada global. 


\begin{tabular}{|c|c|c|c|}
\hline \multicolumn{2}{|c|}{$\begin{array}{l}\text { Custeio-meta } \\
\text {-Processo }\end{array}$} & \multirow{2}{*}{$\begin{array}{c}\begin{array}{c}\text { Fatores que influenciam a } \\
\text { aplicação do } \mathrm{CM}\end{array} \\
\text { 1. Intensidade de competição }\end{array}$} & \multirow{2}{*}{$\begin{array}{l}\text { Contexto ideal a partir dos casos apresentados por Cooper e Slagmulder (1997) } \\
\text { CM é indicado para empresas que adotam estratégias de confronto em situações de baixas } \\
\text { margens de lucro e baixa fidelidade dos clientes. }\end{array}$} \\
\hline \multirow{4}{*}{ 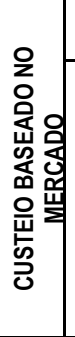 } & & & \\
\hline & \multirow{3}{*}{ 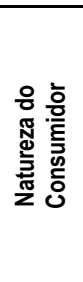 } & 2. Grau de sofisticação do cliente & $\begin{array}{l}\text { CM é aplicável em ambientes com clientes com alto grau de sofisticação (capazes de detectar } \\
\text { diferenças entre preço, qualidade e funcionalidade entre produtos concorrentes), quando a } \\
\text { zona de sobrevivência é estreita e o produto deve ser projetado de modo a atender ao máximo } \\
\text { os requisitos do cliente. }\end{array}$ \\
\hline & & $\begin{array}{l}\text { 3. A frequência com que as } \\
\text { exigências dos clientes mudam }\end{array}$ & $\begin{array}{l}\text { CM pode trazer mais benefícios quando as preferências dos clientes mudam rapidamente, pois } \\
\text { nessas condições a empresa corre o risco de lançar produtos potencialmente fora da zona de } \\
\text { sobrevivência. }\end{array}$ \\
\hline & & $\begin{array}{l}\text { 4. Grau de entendimento sobre os } \\
\text { requisitos futuros do produto }\end{array}$ & $\begin{array}{l}\text { À medida que o entendimento sobre os requisitos futuros dos clientes aumenta, cresce a } \\
\text { importância da participação dos clientes na determinação da zona de sobrevivência. }\end{array}$ \\
\hline \multirow{6}{*}{ 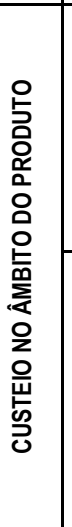 } & \multirow{3}{*}{ 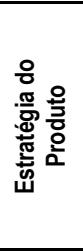 } & $\begin{array}{l}\text { 5. Variedade de produtos sendo } \\
\text { produzidos }\end{array}$ & $\begin{array}{l}\text { Os benefícios do emprego do CM aumentam à medida que a quantidade de produtos diferentes } \\
\text { aumenta, pois a quantia de recursos envolvidos é maior, e isso torna mais interessante o } \\
\text { esforço na direção da redução dos riscos. }\end{array}$ \\
\hline & & $\begin{array}{l}\text { 6. Frequência de lançamentos de } \\
\text { modelos revisados/atualizados }\end{array}$ & $\begin{array}{l}\text { Quando a empresa precisa lançar produtos com novas características, frequentemente, a } \\
\text { abordagem CM pode ser muito benéfica, pois os investimentos iniciais e o risco são altos. }\end{array}$ \\
\hline & & 7. Grau de inovação do produto & $\begin{array}{l}\text { É mais difícil aplicar CM em produtos revolucionários, pois é difícil estabelecer o preço final, } \\
\text { bem como estimar o valor a ser percebido pelo cliente. Também podem faltar dados históricos } \\
\text { de custo e dados sobre novos fornecedores que se envolverão no processo. }\end{array}$ \\
\hline & \multirow{3}{*}{ 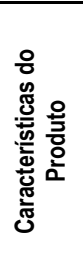 } & 8. Complexidade do produto & $\begin{array}{l}\text { A medida que aumenta a complexidade, aumentam os beneficios do CM. Há meios de } \\
\text { simplificar o CM. }\end{array}$ \\
\hline & & $\begin{array}{l}\text { 9. Investimento inicial necessário } \\
\text { para se produzir }\end{array}$ & $\begin{array}{l}\text { Os benefícios do CM serão maiores em empresas cujo investimento inicial é alto, pois cada } \\
\text { produto precisa atingir a máxima probabilidade de ter sucesso no lançamento. CM desempenha } \\
\text { importante papel na garantia da margem de lucro. Life-cycle costing é especialmente } \\
\text { importante. }\end{array}$ \\
\hline & & $\begin{array}{l}\text { 10. Duração da fase de } \\
\text { desenvolvimento de produto }\end{array}$ & $\begin{array}{l}\text { CM é mais benéfico aplicado a produtos cuja fase de desenvolvimento é longa, pois a demora } \\
\text { entre o projeto e o lançamento aumenta o risco de fracasso no mercado. Porém requer-se um } \\
\text { processo de CM mais formal e cuidadoso. }\end{array}$ \\
\hline \multirow{3}{*}{ 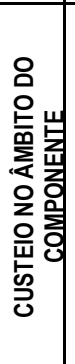 } & \multirow{3}{*}{ 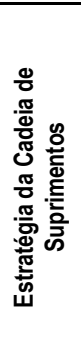 } & $\begin{array}{l}\text { 11. Grau de integração horizontal } \\
\text { (número de produtos/serviços } \\
\text { terceirizados) }\end{array}$ & $\begin{array}{l}\text { Há dois fatores principais que maximizam os beneficios do CM em empresas com integração } \\
\text { horizontal: (a) quando há muitos componentes terceirizados, os custos-meta estabelecidos } \\
\text { criam pressão sobre os fornecedores, reduzindo os preços; (b) o retorno advindo do } \\
\text { investimento na criatividade dos fornecedores é considerável, pois eles não apenas fornecem } \\
\text { grande parte dos componentes, mas também se tornam responsáveis pelo projeto. }\end{array}$ \\
\hline & & $\begin{array}{l}\text { 12. Influência sobre os } \\
\text { fornecedores }\end{array}$ & $\begin{array}{l}\text { Quanto maior o poder da empresa sobre seus fornecedores, mais benefícios serão colhidos da } \\
\text { pressão exercida sobre eles. Do contrário, os benefícios serão reduzidos, como ocorre na } \\
\text { construção civil. }\end{array}$ \\
\hline & & $\begin{array}{l}\text { 13. Relação entre produtor } \\
\text { (comprador) e sua cadeia de } \\
\text { suprimentos }\end{array}$ & $\begin{array}{l}\text { O cerne do aumento dos benefícios da aplicação de CM está na capacidade de ambas as } \\
\text { partes, comprador e fornecedor, combinarem a criatividade projetual na direção de melhores } \\
\text { meios para reduzir custos. Essa cooperação pode ser suplementada por uma série de técnicas } \\
\text { interorganizacionais de gestão de custo. }\end{array}$ \\
\hline
\end{tabular}

Quadro 1 - Fatores que influenciam o processo de custeio-meta

Fonte: adaptado de Cooper e Slagmulder (1997).

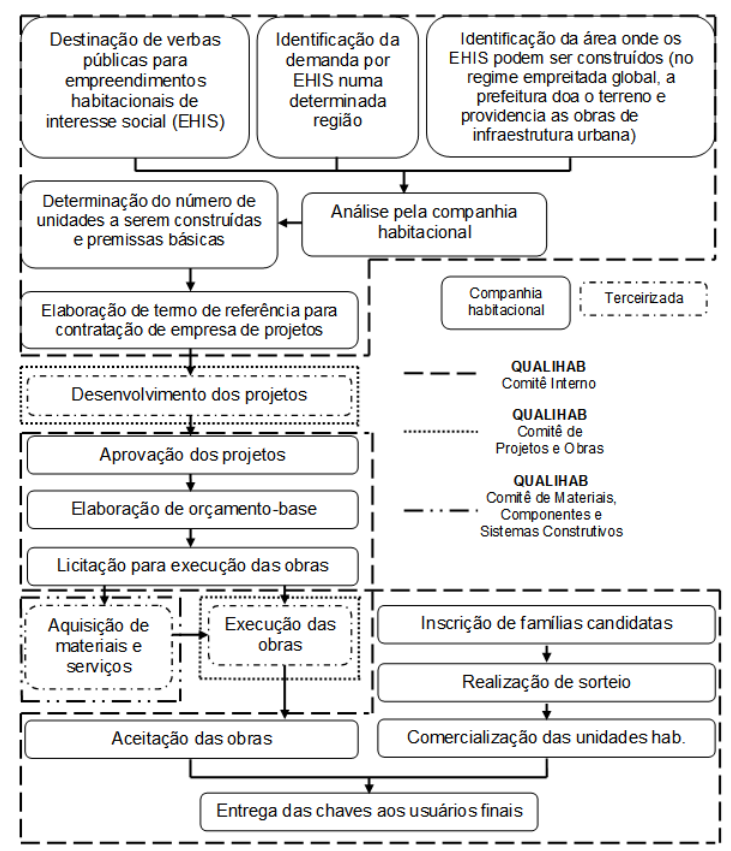

Figura 1 - Desenvolvimento de EHIS em regime de contratação por empreitada global na Companhia de Habitação A

58 Granja, A. D.; Jacomit, A. M.; Guadanhim, S. J.; Hirota, E. H. 
Nessa opção, a prefeitura municipal é envolvida e é responsável pela doação do terreno e pela execução das obras de infraestrutura urbana. $\mathrm{O}$ promotor financeiro é a companhia habitacional. A partir daí a companhia habitacional inicia seu processo de análise interna do empreendimento, com a identificação das necessidades dos futuros usuários e definição de metas para o empreendimento, como o número de unidades habitacionais a serem construídas e destinação de verbas. Em geral, é contratada, então, a empresa que fará o levantamento topográfico e as sondagens no terreno para elaboração do projeto de fundações. Após essa etapa, a companhia elabora o termo de referência (TR) para a contratação de projetos completos e de serviços de aprovação, que oferece diretrizes gerais para auxiliar na elaboração do projeto por empresa terceirizada, junto com o manual técnico de projetos. Após a aceitação dos projetos pela companhia, o orçamento básico é elaborado e, após sua aprovação, inicia-se o processo licitatório para a execução das obras. No processo licitatório para o regime de execução de empreitada a preço global, o valor global de referência é determinado pelo orçamento elaborado pela companhia habitacional. A empresa vencedora da licitação será aquela que apresentar o maior desconto em relação a esse preço, não podendo o desconto ser superior a $25 \%$ do preço global de referência. No decorrer da execução da obra, ocorre o cadastro das famílias candidatas e a realização de sorteio para a determinação dos futuros mutuários. As unidades habitacionais são, então, comercializadas e entregues aos seus moradores, após a aceitação das obras pela companhia habitacional.

\section{Oportunidades e barreiras para a aplicação do $\mathrm{CM}$ em EHIS com base nos fatores de Cooper e Slagmulder (1997)}

A partir da análise dos fatores que influenciam uma aplicação do CM segundo Cooper e Slagmulder (1997) e da análise do contexto de EHIS, foram identificadas algumas oportunidades e limitações para a aplicação do CM por uma companhia habitacional no desenvolvimento de EHIS (Quadro 2). No contexto de EHIS esses fatores exerceriam a mesma influência que teriam numa aplicação na manufatura, com exceção de dois fatores:

(a) intensidade de competição; e

(b) grau de sofisticação do cliente.

No contexto de EHIS a concorrência é muito baixa, quase inexistente, e o nível de sofisticação dos clientes é baixo tomando como base a seletividade e a exigência das suas escolhas.
Entretanto, não se pode afirmar que esses fatores irão implicar um alargamento da zona de sobrevivência ${ }^{1}$ (COOPER; SLAGMULDER, 1997), já que a pressão para a redução de custos, promovida pela concorrência e pelos clientes no caso da manufatura, é exercida pelos órgãos financiadores no caso de EHIS. Todavia, não se pode dizer o mesmo a respeito das exigências para o aumento da funcionalidade e da qualidade.

No contexto de EHIS, quatro dos fatores coincidem com o contexto ideal $(7,8,9$ e 11) e sete diferem $(3,4,5,6,10,12$ e 13$)$, descartando os dois primeiros fatores (1 e 2), que exercem influência diferente em EHIS, como comentado anteriormente. Entretanto, os sete fatores que diferem do contexto ideal, isoladamente, não podem ser apontados como barreiras para uma aplicação do CM em EHIS. Em geral, a influência que eles exercem é localizada e não impede a aplicação do CM como um todo. Mesmo a baixa cooperação entre o produtor e a sua cadeia de suprimentos, o que dificultaria o processo de redução de custos por meio de negociação com fornecedores e aperfeiçoamento dos componentes numa aplicação do $\mathrm{CM}$, não pode ser considerada uma barreira. Nesse caso, o CM poderia auxiliar ainda no alinhamento do produto com o mercado, no gerenciamento proativo dos custos e na redução de custos a partir da análise de soluções de projeto e EV, por exemplo.

Com relação ao exposto anteriormente, é importante ressaltar que Cooper e Slagmulder (1997) argumentam, com base nos casos por eles analisados, que o custeio-meta foi abordado por meio de uma estrutura comum a todos os casos, porém houve diferenças entre as análises devido a alguns dos fatores intervenientes. Assim, um contexto ideal para aplicação do custeio-meta foi proposto para cada fator, com base em seu potencial de potencialização de benefícios advindos com a sua adoção. Entretanto, a influência de cada fator não se estende a todo o PDP com aplicação de custeio-meta, ou seja, analisando-se cada um individualmente, por mais que o contexto de análise seja desfavorável para a aplicação do CM, sempre permanecem outras possibilidades para aperfeiçoamento do PDP. Por outro lado, existem fatores que influenciam múltiplas partes do PDP com aplicação de CM e desempenham um papel de destaque na

\footnotetext{
${ }^{1}$ Cada produto colocado à venda por uma empresa apresenta valores distintos em termos de preço, funcionalidade e qualidade (tripé de sobrevivência). A chance de sucesso depende da aceitação pelo cliente do valor incorporado no produto desses itens. A zona de sobrevivência de um produto se constitui na região que define os valores viáveis (feasible) e permissíveis (allowable) para cada uma das três dimensões do tripé de sobrevivência (COOPER; SLAGMULDER, 1997).
} 
modelagem do $\mathrm{CM}$ ao contexto de análise. Entre esses fatores pode-se mencionar a intensidade de competição e o grau de inovação do produto (COOPER; SLAGMULDER, 1997).

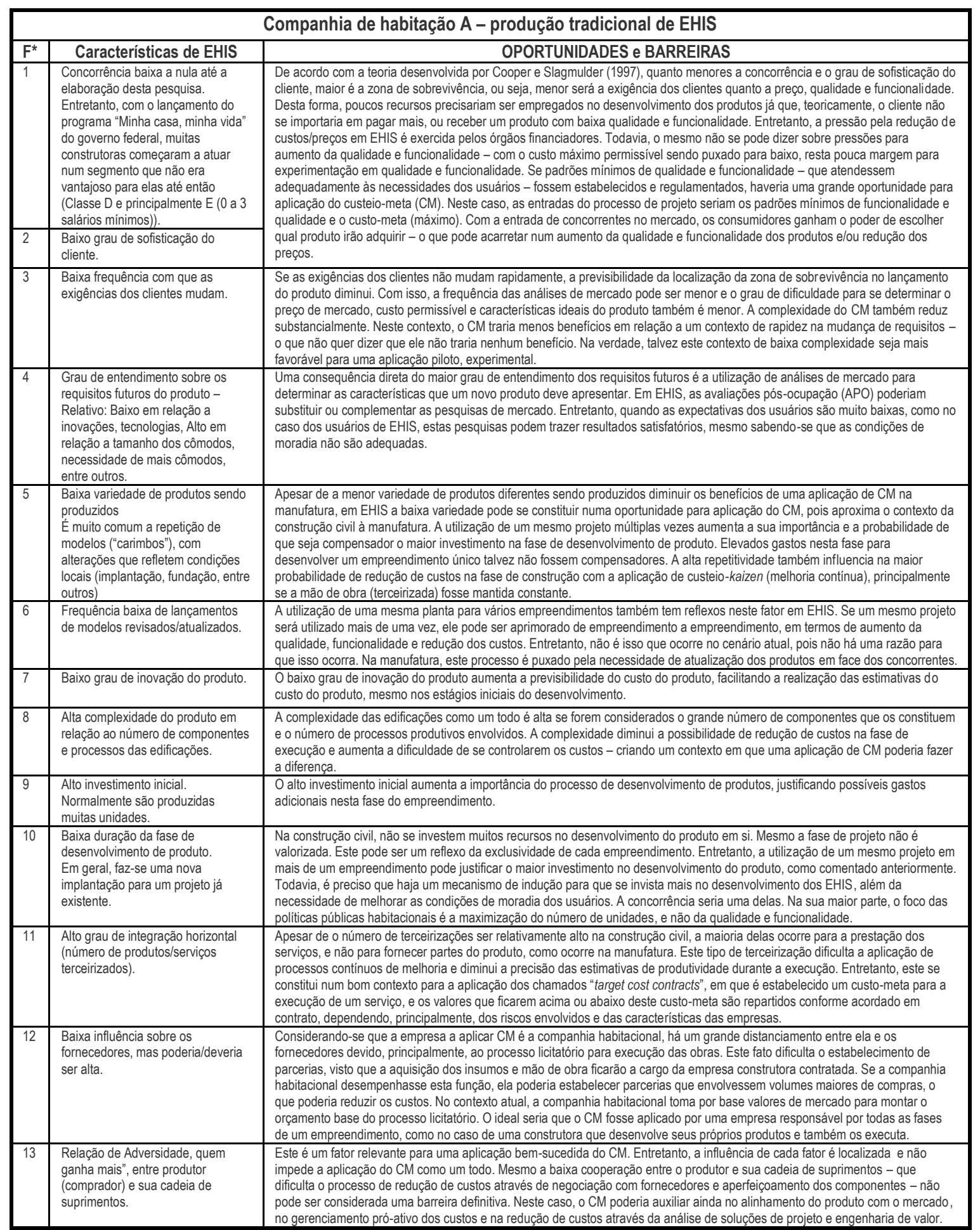

Quadro 2 - Oportunidades e barreiras para a aplicação do custeio-meta com base no estudo realizado na Companhia de Habitação A

Nota: *Numeração de fatores propostos por Cooper e Slagmulder (1997), elencados no Quadro 1 deste artigo. 
Já os quatro fatores que coincidem em EHIS e no contexto ideal - grau de inovação do produto, investimento inicial necessário para se produzir, a alta complexidade do produto e o elevado número de terceirizações - podem ser considerados como oportunidades para uma aplicação do CM em EHIS por uma companhia habitacional. O baixo grau de inovação do produto aumenta a previsibilidade de seu custo, facilitando a realização das estimativas, mesmo nos estágios iniciais do desenvolvimento. $\mathrm{O}$ alto investimento inicial aumenta a importância do processo de desenvolvimento de produtos, justificando possíveis gastos adicionais nessa fase do empreendimento.

A complexidade das edificações como um todo é alta se forem considerados o grande número de componentes que as constituem e o número de processos produtivos envolvidos. Tal complexidade diminui a possibilidade de redução de custos na fase de execução e aumenta a dificuldade de se controlarem os custos, criando um contexto em que uma aplicação do $\mathrm{CM}$ poderia trazer benefícios.

Apesar de o número de terceirizações ser relativamente alto na construção civil, a maioria delas ocorre para a prestação dos serviços, e não para fornecer partes do produto, como ocorre na manufatura. Este tipo de terceirização dificulta a aplicação de processos contínuos de melhoria e diminui a precisão das estimativas de produtividade durante a execução. Entretanto, este se constitui num bom contexto para a aplicação dos chamados "target cost contracts", em que é estabelecido um custo-meta para a execução de um serviço, e os valores que ficarem acima ou abaixo desse custo-meta são divididos conforme acordado em contrato, dependendo, principalmente, dos riscos envolvidos e das características das empresas (BROOME; PERRY, 2002). Robert e Granja (2006) registraram bons resultados com uma aplicação semelhante.

\section{O processo de desenvolvimento de EHIS na Companhia de Habitação B}

O PAR apresenta algumas características favoráveis à aplicação do $\mathrm{CM}$, como perfil do cliente bem definido dentro do processo, envolvimento de agentes financiadores, executores e promotores em todo o processo de desenvolvimento do produto, e definição dos projetos, administração e construção das obras a cargo de construtoras, as quais possuem interesse financeiro no projeto. Além disso, a existência de dados em abundância sobre satisfação do cliente voltada à habitação social favorecem a implementação dessa estratégia, gerando oportunidades para o desenvolvimento de produtos estritamente voltados para esse público-alvo.

\section{Programa PAR - PDP e processo de projeto}

No mapeamento do PDP do PAR analisado por Gomes, Guadanhim e Hirota (2006), a etapa de pré-projeto dos empreendimentos, na qual são definidas as diretrizes gerais e estabelecidos critérios delimitadores das características do empreendimento, tem a participação de um grande número de agentes (Caixa Econômica Federal CAIXA, construtora, imobiliária responsável pela administração do futuro condomínio, companhia de habitação local, Ministério das Cidades MinCidades e o arrendatário). O MinCidades e a CAIXA são os principais balizadores desse processo. Nessa etapa, muitas das restrições observadas no estudo desenvolvido tiveram origem nas determinações da CAIXA.

Como o objetivo da fase de pré-projeto é a análise do mercado, além dos dados relativos ao déficit habitacional local e da disponibilidade de recursos fornecidos pelo MinCidades e CAIXA para análise de viabilidade, é fundamental que se obtenham informações sobre os requisitos dos usuários a serem atendidos. No mapeamento analisado, a participação dos usuários na fase de pré-projeto é limitada ao fornecimento de informações por ocasião de seu cadastramento como interessado na aquisição da habitação. Os autores do estudo apontam o caráter burocrático dessa coleta como uma deficiência no PDP analisado e propõem alterações no instrumento de coleta, de forma a se obterem informações relevantes para a captura de requisitos de usuários. Da mesma forma, a participação da imobiliária, empresa contratada para administrar os imóveis em uso, se restringe ao fornecimento de informações burocráticas para sua contratação, quando poderia fornecer informações importantes acerca do perfil de uso e de custos de operação e manutenção das edificações para o desenvolvimento dos projetos.

Observa-se, então, que a estrutura do PDP do PAR permite a inserção de alterações operacionais, de modo a propiciar uma avaliação mais adequada para maior agregação de valor ao produto EHIS. No entanto, é importante analisar o processo de negócio desse programa, ou seja, como se estabelecem as relações entre os diferentes agentes desse processo no que se refere aos interesses individuais. Por se tratar de um contexto social e de interesse público, a obtenção de lucro na análise da estratégia do CM deve ser substituída pelo atingimento dos objetivos e pela entrega de valor a cada agente. 
Segundo Simões, Takinami e Hirota (2008), a cadeia de negócios se estabelece a partir da interação dos processos de negócio de cada agente no processo de desenvolvimento de um empreendimento PAR. A identificação da demanda realizada pela Companhia de Habitação (COHAB) local traz vantagens à cadeia, já que define a demanda em termos da quantidade e qualidade, fazendo com que o projeto seja direcionado ao atendimento da demanda e com que haja agilidade no processo de arrendamento das unidades habitacionais. Essas informações também são importantes para que a empresa faça de forma adequada a análise da qualidade econômica e financeira do empreendimento. $\mathrm{O}$ incentivo à participação de empresas construtoras qualificadas nessa cadeia é fundamental para o sucesso do PAR.

Os processos de desenvolvimento do projeto, análise da proposta, alterações de tipologia e tecnologia, novo projeto e reanálise do projeto indicam um gargalo na definição do produto, trazendo custos adicionais para o projeto, prazos maiores na realização do empreendimento e menor rentabilidade para o empreendedor, ocasionando redução da oferta de empreendimentos para o mercado.

$\mathrm{O}$ aspecto mais relevante na análise da cadeia de processos de negócios sob a ótica do $\mathrm{CM}$ é a participação tardia dos fornecedores de materiais e componentes. Não há participação desses agentes nas etapas de definição do produto. Somente após a aprovação do financiamento pela CAIXA a empresa construtora faz o contato com os fornecedores para a aquisição dos materiais e componentes. Essa característica decorre, principalmente, dos procedimentos burocráticos adotados pelo agente financeiro (CAIXA), cujo processamento é demorado (podendo chegar a 24 meses), e da falta de foco no cliente, observada em todo o processo analisado.

\section{Oportunidades e barreiras - PAR}

O Quadro 3 apresenta uma síntese das oportunidades e barreiras identificadas no processo de desenvolvimento de EHIS no PAR. Embora ele apresente uma série de características do PAR que, em princípio, favorecem a aplicação de uma estratégia como o CM no desenvolvimento de empreendimentos com maior valor agregado, é preciso reconhecer também a necessidade de mudanças culturais e de arranjos interorganizacionais.

Parece haver uma clara sinalização de que uma postura que valoriza o processo de projeto e a fase de desenvolvimento do produto, embora demande mais tempo, tende a reduzir os custos e o tempo de execução. Se consideradas a demanda e a produção nacional, há mercado suficientemente amplo para a produção de determinados componentes em série, com grandes ganhos em escala.

Tais possibilidades, evidentemente, dependem de alterações importantes na indústria da construção civil, que possui características próprias, como, por exemplo, o conservadorismo - o combustível para a quebra de inércia pode ser justamente a gestão eficiente de custos, que traz como consequência desejável a certeza de lucratividade, motor principal para alavancar transformações. Verificase, assim, que o PAR constitui-se num campo fértil para investigação, cujas bases possuem características que tangenciam a teoria do $\mathrm{CM}$ e realmente oferecem oportunidades de grande melhoria na produção de habitação, malgrado as previsíveis dificuldades apontadas. 


\begin{tabular}{|c|c|c|c|}
\hline \multicolumn{4}{|c|}{ Companhia de Habitação B - Produção de EHIS pelo PAR } \\
\hline $\mathbf{F}^{*}$ & Características do Programa & \multicolumn{2}{|c|}{ OPORTUNIDADES E BARREIRAS } \\
\hline 1 & $\begin{array}{l}\text { Relativa intensidade de competição. O ambiente } \\
\text { competitivo é característica do PAR nessa fase, pois a } \\
\text { proposição do empreendimento é aberta à iniciativa } \\
\text { privada, responsável pela elaboração dos estudos de } \\
\text { viabilidade e projetos, enquadramento do produto no } \\
\text { preço final preestabelecido pelo Programa e aprovação } \\
\text { junto à Caixa. }\end{array}$ & \multicolumn{2}{|c|}{$\begin{array}{l}\text { OPORTUNIDADES: as propostas mais consistentes e de maior qualidade, com o mesmo } \\
\text { orçamento, são aprovadas. De certa forma existe um custo-meta previamente estabelecido e a } \\
\text { diferenciação deve vir das outras componentes do tripé. } \\
\text { BARREIRAS: o ambiente competitivo não ocorre no nível da qualidade, mas predomina nas } \\
\text { concorrências públicas baseadas em menor preço, com consequente sacrifício exagerado de } \\
\text { funcionalidade e qualidade. }\end{array}$} \\
\hline 2 & $\begin{array}{l}\text { Grau de sofisticação do cliente crescente. Na faixa de } \\
\text { renda mínima (cerca de } \mathrm{R} \$ 1.800,00) \text {, as exigências do } \\
\text { usuário são maiores no Programa PAR do que em } \\
\text { programas tradicionais de provisão de HIS. }\end{array}$ & $\begin{array}{l}\text { OPORTUNIDADES: a maior exigência baliza as } \\
\text { características do produto final. Por exemplo, é comum o } \\
\text { usuário exigir vaga de estacionamento, preferencialmente } \\
\text { coberta. }\end{array}$ & \multirow{3}{*}{$\begin{array}{l}\text { BARREIRAS: apesar da } \\
\text { existência de ferramentas e dados } \\
\text { referentes ao perfil do usuário } \\
\text { final, seus anseios e capacidade } \\
\text { de endividamento, a repetição de } \\
\text { modelos e tipologias usados } \\
\text { historicamente no Brasil indica } \\
\text { pouca dedicação na fase inicial } \\
\text { de concepção do produto de } \\
\text { modo a agregar valores } \\
\text { apropriados a contextos } \\
\text { específicos. Isso é verificado nas } \\
\text { constantes reformas observadas - } \\
\text { apesar da proibição - } \\
\text { principalmente em unidades } \\
\text { unifamiliares implantadas em } \\
\text { loteamentos tradicionais. }\end{array}$} \\
\hline 3 & $\begin{array}{l}\text { Baixa frequência com que as exigências dos clientes } \\
\text { mudam. É determinante a capacidade de endividamento } \\
\text { do usuário final, a qual determina preço e é critério } \\
\text { básico para inscrição no Programa. A referência de } \\
\text { mercado local, o que inclui o preço dos terrenos, pode } \\
\text { variar conforme a localização. }\end{array}$ & $\begin{array}{l}\text { OPORTUNIDADES: pesquisa em APO e gestão de } \\
\text { requisitos de clientes avançou muito no Brasil. Há } \\
\text { abundância de dados que podem subsidiar decisões de } \\
\text { projeto que atendam às exigências do perfil do usuário a ser } \\
\text { atingido e suas variações. O preço final estabelecido } \\
\text { enquadra-se na realidade imobiliária e, de certa forma, } \\
\text { acompanha as mudanças de perfil do cliente. }\end{array}$ & \\
\hline 4 & $\begin{array}{l}\text { Baixo grau de entendimento sobre os requisitos futuros } \\
\text { do produto. O Ministério das Cidades, através da Caixa } \\
\text { Econômica Federal como gestor do programa, atuando } \\
\text { em conjunto com outros órgãos públicos de esferas } \\
\text { nacionais e locais, define políticas e diretrizes e aloca } \\
\text { recursos, após identificar e selecionar a demanda. }\end{array}$ & & \\
\hline 5 & Baixa variedade de produtos sendo produzidos. & \multicolumn{2}{|c|}{$\begin{array}{l}\text { OPORTUNIDADES: apesar da tendência à repetição de tipologias tradicionais, tem-se observado, } \\
\text { quando consideradas a produção de EHIS pelo Programa em âmbito nacional, uma diversidade } \\
\text { considerável de soluções. O estabelecimento de um leque amplo de possibilidades de projeto com a } \\
\text { aplicação de TC poderia resultar nos benefícios apontados na literatura. }\end{array}$} \\
\hline 6 & $\begin{array}{l}\text { Baixa frequência de lançamentos de modelos } \\
\text { revisados/atualizados, com tendência de acréscimo, } \\
\text { pois nessa faixa de renda o programa enfrenta a } \\
\text { concorrência de outros empreendimentos da iniciativa } \\
\text { privada. }\end{array}$ & \multicolumn{2}{|c|}{$\begin{array}{l}\text { BARREIRAS: as características básicas das unidades são as mesmas há décadas. Há pouquíssima } \\
\text { aplicação dos avanços das pesquisas na área. }\end{array}$} \\
\hline 7 & $\begin{array}{l}\text { Baixo grau de inovação do produto. A construção civil } \\
\text { no Brasil possui perfil conservador. A fase de } \\
\text { desenvolvimento do produto, em especial pré-projeto e } \\
\text { projeto, não recebe recursos suficientes. }\end{array}$ & \multicolumn{2}{|c|}{$\begin{array}{l}\text { OPORTUNIDADES: o conservadorismo favorece a disponibilidade de dados históricos confí́veis, seja } \\
\text { para o estabelecimento dos custos-meta, seja para a análise de satisfação ou previsão de custos de } \\
\text { manutenção. }\end{array}$} \\
\hline 8 & $\begin{array}{l}\text { Alta complexidade do produto, apesar da baixa } \\
\text { tecnologia empregada. }\end{array}$ & \multicolumn{2}{|c|}{$\begin{array}{l}\text { OPORTUNIDADES: o edifício habitacional é extremamente complexo, pois seus elementos passam a } \\
\text { acumular muito mais do que valores funcionais. O espaço arquitetônico e suas características geram } \\
\text { valores subjetivos e não mensuráveis facilmente. } \\
\text { BARREIRAS: a complexidade é tamanha que a decomposição do edifício em elementos funcionais } \\
\text { constitui-se num desafio enorme, pois valores subjetivos são difíceis de identificar, qualificar e } \\
\text { quantificar. }\end{array}$} \\
\hline 9 & $\begin{array}{l}\text { Alto investimento inicial necessário para se produzir. } \\
\text { Além de tratar-se de empreendimentos de grande porte, } \\
\text { o custo da terra tem pesado muito, em especial nas } \\
\text { grandes cidades. }\end{array}$ & \multicolumn{2}{|c|}{$\begin{array}{l}\text { OPORTUNIDADES: a aplicação de TC pode ser o instrumento-chave na capacidade de competição e } \\
\text { sobrevivência da empresa construtora vencedora da concorrência pública, pois o descontrole dos custos } \\
\text { tem custado a saúde financeira de empresas e a conclusão de obras. } \\
\text { BARREIRAS: é preciso que as fases de planejamento e desenvolvimento do produto, desde as fases } \\
\text { iniciais, recebam investimento adequado, fato raro no setor atualmente. }\end{array}$} \\
\hline 10 & $\begin{array}{l}\text { Baixa duração da fase de desenvolvimento de produto. } \\
\text { Em geral o tempo e os recursos dedicados ao projeto e } \\
\text { seu desenvolvimento são insuficientes, e soluções tidas } \\
\text { como consagradas são repetidas. }\end{array}$ & \multicolumn{2}{|c|}{$\begin{array}{l}\text { BARREIRAS: empresas construtoras no Brasil, com raras exceções, não possuem controle pleno de } \\
\text { custos e estrutura adequada para aplicação da estratégia recomendada (MARCHESAN, 2001). } \\
\text { Os custos reais não são de fato conhecidos; muitas decisões são baseadas em estimativas e na experiência. } \\
\text { O projeto é tido muitas vezes como mera necessidade formal do que como elemento-chave de todo o } \\
\text { processo. }\end{array}$} \\
\hline 11 & $\begin{array}{l}\text { Alto grau de integração horizontal (número de } \\
\text { produtos/serviços terceirizados). Cada vez as empresas } \\
\text { construtoras são mais enxutas e o número de } \\
\text { terceirizações é crescente. }\end{array}$ & \multicolumn{2}{|c|}{$\begin{array}{l}\text { OPORTUNIDADES: um grande salto possível, e talvez o mais complexo, seria o credenciamento prévio } \\
\text { dos fornecedores pelo gestor. Essa medida, ao qualificar fornecedores aptos a atender nacional ou } \\
\text { regionalmente o Programa, traria o benefício da escala de produção. } \\
\text { BARREIRAS: o custo é composto de preços dos fornecedores, não pela somatória dos custos de cada } \\
\text { elemento ou sistema; o estor industrial é muito mais disciplinado que a construção civili; as técnicas mais } \\
\text { avançadas de construção e padronização de componentes são pouco usadas (MINISTÉRIO DO } \\
\text { DESENVOLVIMENTO, INDÚSTRIA E COMÉRCIO EXTERIOR, 2003); há barreiras econômicas e } \\
\text { culturais para a industrialização da construção civil (MINISTÉRIO DO DESENVOLVIMENTO, } \\
\text { INDÚSTRIA E COMÉRCIO EXTERIOR, 2003); ineficiência de programas e políticas governamentais } \\
\text { que garantam estabilidade e averiguem qualidade do produto HIS (MINISTÉRIO DO } \\
\text { DESENVOLVIMENTO, INDÚSTRIA E COMÉRCIO EXTERIOR, 2003). }\end{array}$} \\
\hline 12 & $\begin{array}{l}\text { Baixa influência sobre os fornecedores, apesar da al } \\
\text { demanda nacional, a qual permitiria a produção de } \\
\text { determinados componentes em série, com grandes } \\
\text { ganhos em escala. }\end{array}$ & \multicolumn{2}{|c|}{$\begin{array}{l}\text { OPORTUNIDADES: se considerada a demanda nacional por HIS, haveria a possibilidade de } \\
\text { desenvolvimento de produtos especificamente para atender às exigências do Programa. } \\
\text { Componentes desenvolvidos especificamente para o Programa teriam maior possibilidade de atingir o } \\
\text { equilíbrio entre custo e benefício desejado pelo cliente final, alinhando a prática à teoria da estratégia } \\
\text { Target Costing. } \\
\text { BARREIRAS: } \\
\text { constrústrias de componentes e materiais para construção civil são muito maiores do que as } \\
\text { desenvolvimento e produçãao, precino inversa da desejada, ou seja, as construtoras, responsáveis pelo } \\
\text { de TC, os materiais e componentes deveriam ser desenvolve mercado, enquanto, numa aplicação efetiva } \\
\text { tipologia de EHIS, levando-se em conta principalmente a economia de escala. }\end{array}$} \\
\hline 13 & $\begin{array}{l}\text { Relação entre produtor (comprador) e sua cadeia de } \\
\text { suprimentos de baixa cooperação. As construtoras são } \\
\text { apenas clientes dos grandes fornecedores, o que } \\
\text { enfraquece seu poder de negociação. }\end{array}$ & \multicolumn{2}{|c|}{$\begin{array}{l}\text { OPORTUNIDADES: a criação de mecanismos institucionais que promovam convênios } \\
\text { multidisciplinares e interinstitucionais poderia viabilizar o trabalho conjunto entre fornecedores, } \\
\text { projetistas e construtores, num ambiente parecido com o que ocorre na indústria automobilística, em que } \\
\text { componentes são desenvolvidos sob a coordenação de uma empresa montadora levando em conta } \\
\text { aspectos de qualidade e custo, com ganhos em termos de qualidade e economia. } \\
\text { BARREIRAS: cadeia de suprimentos não atua juntamente com as construtoras no desenvolvimento do } \\
\text { produto ou de componentes. "Custos" são determinados através de cotações entre diversos fornecedores, } \\
\text { sem seu envolvimento pleno; na realidade trabalha-se com preço dos componentes; a estrutura de custos } \\
\text { normalmente é baseada em etapas e sistemas, não em componentes. }\end{array}$} \\
\hline
\end{tabular}

\section{Quadro 3 - Oportunidades e barreiras para a aplicação do custeio-meta com base no estudo realizado} na Companhia de Habitação B

Nota: *Numeração dos fatores propostos por Cooper e Slagmulder (1997), elencados no Quadro 1 deste artigo. 


\section{Comparação de resultados: Companhia A e Companhia B}

A análise conjunta dos estudos realizados nas Companhias de Habitação A (companhia de habitação estadual com programa próprio) e B (contexto do PAR) por meio das inferências apresentadas nos Quadros 2 e 3 permitiu a elaboração do resumo comparativo apresentado no Quadro 4. Neste quadro destacaram-se algumas das principais semelhanças e diferenças encontradas entre os dois contextos.

As semelhanças apontadas - que refletem não só as características dos casos analisados, mas também da construção civil como um todo podem ser classificadas tanto como barreiras quanto como oportunidades, como discutido nas seções anteriores. As diferenças apontam o contexto da Companhia de Habitação B como um contexto mais favorável à aplicação do $\mathrm{CM}$ se comparado ao da Companhia A, principalmente pela possibilidade de desenvolvimento e execução do empreendimento por um mesmo agente e a existência de concorrência.

Todavia, a implementação do CM no contexto do PAR esbarra em obstáculos ainda difíceis de ser contornados. O ambiente competitivo, definido pela participação das construtoras, não ocorre no nível da qualidade, mas nas concorrências públicas baseadas em menor preço. Nesse momento, os fornecedores ainda não foram escolhidos, um entrave para a implementação do CM. A atuação tardia da cadeia de suprimentos constitui-se numa barreira para a seleção de tecnologias e do estudo de tipologia.

Os fornecedores de materiais de construção, especialmente no Brasil, frequentemente são organizações de porte maior do que as empresas construtoras, o que limita a margem de negociação. Além disso, há dificuldades no desenvolvimento de análises do custo ao longo do ciclo de vida devido à falta de informações de qualidade para a realização delas. Apesar dessas dificuldades, é preciso ressaltar a necessidade de valorização do processo de projeto e das fases iniciais de desenvolvimento do produto. Embora demande mais tempo, o investimento nas etapas de concepção e projeto tende a reduzir os custos do empreendimento e o tempo de execução, principalmente considerando que alguns programas efetivamente produzem EHIS em série. Grandes quantidades produzidas regional ou nacionalmente poderiam viabilizar a aplicação dos princípios do $\mathrm{CM}$ mediante a racionalização da construção, aplicável na maioria dos casos.

\begin{tabular}{|c|}
\hline Semelhanças entre o contexto da Empresa A e o da Empresa B \\
\hline $\begin{array}{l}\text { Baixo grau de inovação do produto. } \\
\text { Baixa duração da etapa de desenvolvimento de produto. } \\
\text { Alto investimento inicial para se produzir. } \\
\text { Baixa variedade de produtos sendo produzidos. } \\
\text { Alta complexidade do produto. } \\
\text { Alto grau de integração horizontal. } \\
\text { Baixa influência do produtor sobre seus fornecedores. } \\
\text { Relação de adversidade entre o produtor e sua cadeia de suprimentos. }\end{array}$ \\
\hline Diferenças entre o contexto da Empresa A e o da Empresa B \\
\hline $\begin{array}{l}\text { No contexto da empresa B, o processo licitatório ocorre numa etapa muito anterior (estudo de viabilidade) } \\
\text { se comparado ao da empresa B (execução da obra). Como na empresa B o agente a desenvolver o } \\
\text { empreendimento é o mesmo que irá executá-lo, uma aplicação do custeio-meta nesse contexto poderia } \\
\text { trazer mais benefícios. } \\
\text { Na atuação da empresa B, os usuários possuem renda familiar a partir de } \mathrm{R} \$ 1.800,00 \text { e apresentam maior } \\
\text { grau de sofisticação (capazes de detectar diferenças entre preço, qualidade e funcionalidade entre produtos } \\
\text { concorrentes). Já na empresa A, o perfil do usuário atendido se inicia na classe E, com renda familiar de } 0 \\
\text { a } 3 \text { salários mínimos (SM), indo até a classe } \mathrm{D} \text {, com } 3 \text { a } 8 \mathrm{SM} \text {. } \\
\text { O preço da unidade é diferenciado entre os dois contextos analisados. } \\
\text { No contexto da empresa B, a intensidade de competição é maior se comparada à da empresa A } \\
\text { (praticamente nula). A maior intensidade de concorrência no contexto da empresa B permite ao usuário } \\
\text { escolher qual é o empreendimento mais adequado para satisfazer os anseios e as necessidades de sua } \\
\text { família. } \\
\text { No contexto da empresa B, há maior variedade de tipologias ofertadas de produto quando comparado à } \\
\text { empresa A. Dessa forma, os usuários dos empreendimentos desenvolvidos pela empresa B podem ter suas } \\
\text { necessidades atendidas de maneira mais adequada. }\end{array}$ \\
\hline
\end{tabular}

Quadro 4 - Algumas das principais semelhanças e diferenças encontradas entre o contexto das Companhias de Habitação A e B

64 Granja, A. D.; Jacomit, A. M.; Guadanhim, S. J.; Hirota, E. H. 


\section{Conclusões}

Os resultados obtidos permitem concluir que o PAR, adotado na Companhia de Habitação B, reúne condições mais propícias para uma eventual adoção do CM no desenvolvimento de seus produtos do que o modelo tradicional de provisão habitacional da Companhia A. Dentro do referencial teórico de fatores que podem favorecer uma aplicação do CM, encontram-se na Companhia $\mathrm{B}$ aspectos que podem influenciar positivamente a adoção do $\mathrm{CM}$, entre outros:

(a) o agente que desenvolve o empreendimento é o mesmo que irá executá-lo;

(b) presença de usuários com maior grau de exigência no que se refere a qualidade, funcionalidade e preço; e

(c) maior intensidade de competição, que propicia maiores escolhas aos futuros usuários.

Outros fatores são comuns aos dois programas analisados e mesclam tanto aspectos favoráveis como desfavoráveis para a adoção do CM nesse contexto.

As inferências obtidas com esta pesquisa permitiram vislumbrar um potencial favorável para a adoção do CM por empresas atuantes no programa "MINHA CASA, MINHA VIDA" (MCMV), promovido pelo Governo Federal e pela CAIXA. Isso se deve ao fato de que, neste programa, um mesmo agente tem a possibilidade de desenvolver os empreendimentos que irá executar, o que permite maior controle sobre as variáveis construtivas, aspectos de construtibilidade, dados de produtividade e custos. Além disso, o nível mais elevado de concorrência nesse programa pode desencadear uma busca pela otimização dos custos construtivos e por diferenciais competitivos, permitindo ao cliente exercer escolhas para melhor atender a suas necessidades. O financiamento do governo e a oferta de subsídios significativos motivaram a entrada das construtoras num segmento que antes era pouco atrativo para elas e que agora já está se constituindo em um atrativo para grandes empresas do setor, mesmo com possível redução das margens de lucro.

$\mathrm{O}$ crescimento de incentivos à habitação social pode impulsionar o desenvolvimento de novas técnicas construtivas que baixem os custos produtivos e aumentem a velocidade de execução, apontando para o início de um processo de industrialização da construção civil. A utilização de peças pré-fabricadas, como painéis de materiais alternativos que são apenas montados no canteiro de obras, está sendo apontada como uma tendência para o setor. A avaliação dessas novas tecnologias pode ficar a cargo da implantação efetiva do Sistema Nacional de Avaliação Técnica (SINAT), do Programa Brasileiro de Qualidade para Habitação (PBQP-H), do Ministério das Cidades. Um ambiente de aperfeiçoamento contínuo de produtos com foco no consumidor, contextualizado num regime de concorrência meritória na oferta de habitação de interesse social, pode encontrar nos princípios do $\mathrm{CM}$ as bases para promover esse novo cenário. Por fim, com a análise das oportunidades e barreiras encontradas nos dois casos analisados, e com as diretrizes decorrentes do conjunto dessas características, conclui-se que o custeio-meta pode ser um referencial importante para a redução de custos e entrega de valor em programas habitacionais com características semelhantes ao PAR, como, por exemplo, o MCMV.

\section{Referências}

ANSARI, S.; BELL, J. E.; CAM-I Target Costing Group. Target Costing: the next frontier in strategic cost management. Chicago: Irwin, 1997.

BALLARD, G.; REISER, P. The St. Olaf College Fieldhouse Project: a case study in designing to target cost. In: ANNUAL CONFERENCE OF THE INTERNATIONAL GROUP FOR LEAN CONSTRUCTION, 12., 2004, Elsinore. Anais... Elsinore, 2004.

BALLARD, G. Rethinking Project Definition in Terms of Target Costing. In: ANNUAL CONFERENCE OF THE INTERNATIONAL GROUP FOR LEAN CONSTRUCTION, 14., 2006, Santiago. Anais... Santiago, 2006.

BRASIL. MINISTÉRIO DAS CIDADES. Déficit Habitacional 2008. Brasília: Secretaria Nacional de Habitação, 2010.

BROOME, J.; PERRY, J. G. How Practitioners Set Share Fractions in Target Cost Contracts. International Journal of Project Management, Nova York, v. 20, n. 1, p. 59-66, 2002.

COKINS, G. Integrating Target Costing \& ABC. Journal of Cost Management, p. 13-22, jul./ago. 2002.

COOPER, R.; SLAGMULDER, R. Target Costing and Value Engineering. Portland: Productivity Press, 1997. 379 p. 
GOMES, D. F. O.; GUADANHIM, S. J.;

HIROTA, E. H. Diagnóstico da Gestão dos

Requisitos de Clientes no Processo de

Desenvolvimento do Produto de Empreendimentos

de Habitação de Interesse Social em Londrina, PR.

In: ENCONTRO NACIONAL DE

TECNOLOGIA NO AMBIENTE CONSTRUÍDO, 11., Florianópolis, 2006. Anais... Florianópolis, SC, 2006.

GUADANHIM. S. J.; HIROTA, E. H.; LEAL, J. G. Análise da Aplicabilidade do Target Costing no Contexto de Programas Habitacionais de Interesse Social: um estudo de caso. In: ENCONTRO

NACIONAL DE TECNOLOGIA NO

AMBIENTE CONSTRUÍDO, 13., Canela, 2010.

Anais... Canela: Antac, 2010.

IBUSUKI, U.; KAMINSKI, P. C. Product Development Process with Focus on Value Engineering and Target-Costing: a case study in an automotive company. International Journal of Production Economics, Nova York, v. 105, n. 2, p. 459-474, fev. 2007.

JACOMIT, A. M.; GRANJA, A. D. Análise Crítica da Aplicação do Custeio-Meta no Desenvolvimento de Empreendimentos de Habitação Social. Ambiente Construído, Porto Alegre, v. 10, n. 1, p. 143-162, jan. /mar. 2010.

JACOMIT, A. M.; GRANJA, A. D.; PICCHI, F. A. Target Costing Research Analysis: reflections for construction industry implementation. In: ANNUAL CONFERENCE ON LEAN CONSTRUCTION, 16., 2007, Manchester, UK. Proceedings... Manchester, 2008.

MARCHESAN, P. R. C. Modelo Integrado de Gestão de Custos e Controle da Produção para Obras Civis. 163 f. Porto Alegre. 2001. Dissertação (Mestrado em Engenharia Civil) Programa de Pós-Graduação em Engenharia Civil, Universidade Federal do Rio Grande do Sul, Porto Alegre, 2001.

MINISTÉRIO DO DESENVOLVIMENTO, INDÚSTRIA E COMÉRCIO EXTERIOR. O Futuro da Construção Civil no Brasil: resultados de um estudo de prospecção tecnológica da cadeia produtiva da construção habitacional. São Paulo: Escola Politécnica da USP, 2003.
MIRON, L. I. G. Gerenciamento dos Requisitos dos Clientes de Empreendimentos

Habitacionais de Interesse Social: proposta para o programa integrado entrada da cidade em Porto Alegre, RS. 351 f. Porto Alegre. 2008. Tese (Doutorado em Engenharia Civil) - Escola de Engenharia, Universidade Federal do Rio Grande do Sul, Porto Alegre, 2008.

MIRON, L. I. G.; FORMOSO, C. T. Client Requirement Management in Building Projects. In: CONFERENCE ON THE INTERNATIONAL GROUP FOR LEAN CONSTRUCTION, 11., 2003, Blacksburg. Proceedings... Blacksburg : IGLC, 2003. p. 144-157.

MONDEN, Y. Target Costing and Kaizen Costing. Portland: Productivity Press, 1995. 373 p.

NICOLINI, D. et al. Can Target Costing and Whole Life Costing Be Applied in the Construction Industry? Evidence From Two Case Studies. British Journal of Management, Londres, v. 11, n. 4, p. 303-324, dez. 2000.

ROBERT, G. T.; GRANJA, A. D. Target and Kaizen Costing Implementation in Construction. In: ANNUAL CONFERENCE OF THE INTERNATIONAL GROUP FOR LEAN CONSTRUCTION, 14., 2006, Santiago, Chile. Anais... Santiago, Chile: IGLC, 2006.

SIMÕES, E.; TAKINAMI, F. K.; HIROTA, E. H. Análise de Cadeias de Negócios de Programas Habitacionais: estudo de caso dos Programas PAR e PSH. In: ENCONTRO NACIONAL DE TECNOLOGIA DO AMBIENTE CONSTRUÍDO, 12., 2008, Fortaleza. Anais... Fortaleza: Antac,. 2008.

YOOK, K.; KIM, I.; YOSHIKAWA, T. Target Costing in the Construction Industry: evidence from Japan. Construction Accounting \&

Taxation, v. 15, n. 3, p. 5-18, maio/jun. 2005.

\section{Agradecimentos}

Os autores agradecem ao Programa Habitare, da Financiadora de Estudos e Projetos (FINEP), pelo apoio a esta pesquisa, e à Coordenação de Aperfeiçoamento de Pessoal de Nível Superior (CAPES), pela concessão de bolsa de capacitação.

\section{Revista Ambiente Construído}

Associação Nacional de Tecnologia do Ambiente Construído

Av. Osvaldo Aranha, $99-3^{\circ}$ andar, Centro

Porto Alegre - RS - Brasil CEP $90035-190$

Telefone: +55 (51) 3308-4084

Fax: +55 (51) 3308-4054

www.seer.ufrgs.br/ambienteconstruido

E-mail: ambienteconstruido@ufrgs.br

66 Granja, A. D.; Jacomit, A. M.; Guadanhim, S. J.; Hirota, E. H. 